\title{
A Case of Lagophthalmos after a Corrective Rhinoplasty
}

\author{
Oak-Sung Choo ${ }^{1}$, Sang Young Hong ${ }^{2}$, Seung-Hyun Yoon ${ }^{2}$, and Hyun Jun Kim ${ }^{1}$ \\ ${ }^{1}$ Departments of Otolaryngology, ${ }^{2}$ Physical Medicine and Rehabilitation, School of Medicine, Ajou University, Suwon, Korea
}

\section{비성형술 후에 발생한 토안증 1예}

추옥성 ${ }^{1} \cdot$ 홍상영 $\cdot$ 윤승현 ${ }^{2} \cdot$ 김현준 $^{1}$

아주대학교 의과대학 이비인후과학교실, ${ }^{1}$ 재활의학과 ${ }^{2}$

\author{
Received June 16, 2014 \\ Revised October 7, 2014 \\ Accepted October 13, 2014 \\ Address for correspondence \\ Hyun Jun Kim, MD \\ Department of Otolaryngology, \\ School of Medicine, \\ Ajou University, \\ 164 Worldcup-ro, Yeongtong-gu, \\ Suwon 443-380, Korea \\ Tel $+82-31-219-5262$ \\ Fax $+82-31-219-5264$ \\ E-mailentkhj@ajou.ac.kr
}

Corrective rhinoplasty, a commonly performed plastic surgery, is occasionally followed by numerous risks and complications. In this report, we present, with discussion of the causes and proper management, a case of lagophthalmos that occurred after a rhinoplasty. A 35-year-old female visited our outpatient clinic due to continuous nasal obstruction even after septoplasty. After thorough evaluation, corrective rhinoplasty was performed to release the patient's nasal symptoms and manage the deviated external nose and nasal septum. During the surgery, we encountered excessive nasal bleeding after percutaneous osteotomy. In addition, immediate postoperative findings presented left periorbital edema without limited eye movement or reduced eye vision associated with the paralysis of the eyelid localized to the medial side of the left upper palpebra. Surgeons should be aware of rare but possible complications of corrective rhinoplasty such as lagophthalmos, and a rapid and intensive care is recommended for early management and better prognosis of postoperative complications.

Korean J Otorhinolaryngol-Head Neck Surg 2015;58(1):64-7

Key Words Ecchymosis · Facial paralysis · Lagophthalmos · Osteotomy · Rhinoplasty

\section{Introduction}

Corrective rhinoplasty is a type of plastic surgery for correcting and reconstructing the form, restoring the functions, and aesthetically enhancing the nose. Recently, corrective rhinoplasty has become one of the most commonly performed surgical procedures, due to the rising demands with continuous advancement of the diverse techniques. ${ }^{1)}$ However, rhinoplasty is regarded to be associated with numerous risks and complications. Frequent complications include bleeding or hematoma, infection, deviation or dislocation of the implanted material, absorption of augmentation, and cosmetic dissatisfaction. ${ }^{2)}$ As corrective rhinoplasty may cause various complications, both cosmetically and functionally, a surgeon must be acquainted with the relevant complications and perform the surgery with prudence.
We present a rare case of lagophthalmos as a complication of the corrective rhinoplasty with a discussion of the treatment and review of the literature.

\section{Case}

A 35-year-old female with several years of nasal obstruction was admitted to our outpatient clinic. Two years prior to the visit to our hospital, the patient had undergone a septoplasty at a local clinic, but the obstructive symptom was still remained. Upon review of system, the nasal obstruction was more severe in the left nasal cavity. Through physical examination, the external nose was deviated to the right, and dorsal hump and short nose were observed. Endoscopic findings indicated septal deviation to the left side, synechia developed from the previous septoplasty, and hypertrophy of both infe- 
rior turbinates. Radiologic findings from osteomeatal unit CT confirmed septal deviation to the left side and hypertropic inferior turbinates (Fig. 1). Therefore, a corrective rhinoplasty was performed to release the patient's nasal symptoms and manage the deviated external nose and nasal septum for cosmetic purposes.

Surgical procedures involved revision septoplasty, conchotomies, synechiolysis, and dorsal hump reduction. Extended septal graft and shield graft were also performed to adjust the short nose, and osteotomies were done to correct the deviated external nose. For complete correction and satisfactory repositioning of the bones, percutaneous transverse osteotomy was done on the left medial canthus after left lateral oste-

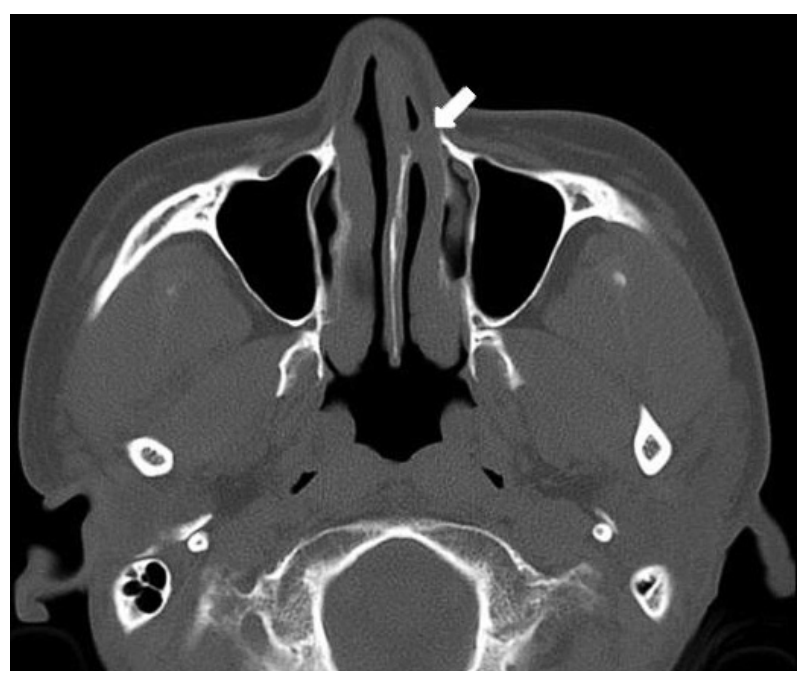

Fig. 1. Preoperative osteomeatal unit CT. Septal deviation to the left side, hypertrophy of both inferior turbinates, synechia in left nasal cavity (arrow) are observed. otomy. During this procedure, we encountered an excessive nasal bleeding which was instantly controlled by topical epinephrine-soaked gauze packing and ice-bag compression. Immediate postoperative findings presented left periorbital edema without limited eye movement or reduced eye vision. Close observation and conservative care were given to the patient. After being discharged from the hospital, the patient was followed up after 7 days of operation. The patient's periorbital edema improved; however, the patient complained of incomplete upper eyelid closure and orbital pain. The paralysis of the eyelid was localized to the medial side of the left upper palpebra (Fig. 2A).

Oral steroid therapy with methylprednisolone was treated to the patient for 3 weeks; $20 \mathrm{mg} /$ day on the first week, $10 \mathrm{mg}$ / day on the second week, and $5 \mathrm{mg} /$ day on the third week. Also, a consultation was made to the ophthalmic department. The patient was diagnosed with lagophthalmos and corneal erosion. Eye drops and patches were prescribed to the patient for conservative care. On the following week, further investigation of the facial nerve was carried out with electromyography (EMG). The results did not show any abnormal findings.

After three weeks of oral steroid therapy and conservative care, the patient's upper eyelid paralysis showed improvement (Fig. 2B). Three months postoperatively, the patient was capable of complete upper eyelid closure (Fig. 2C).

The facial nerve paralysis was reexamined, with the EMG resulting in the normal ranges. During the 6-months of followup and close observation, no evidence of recurrence or additional complications was noticed.
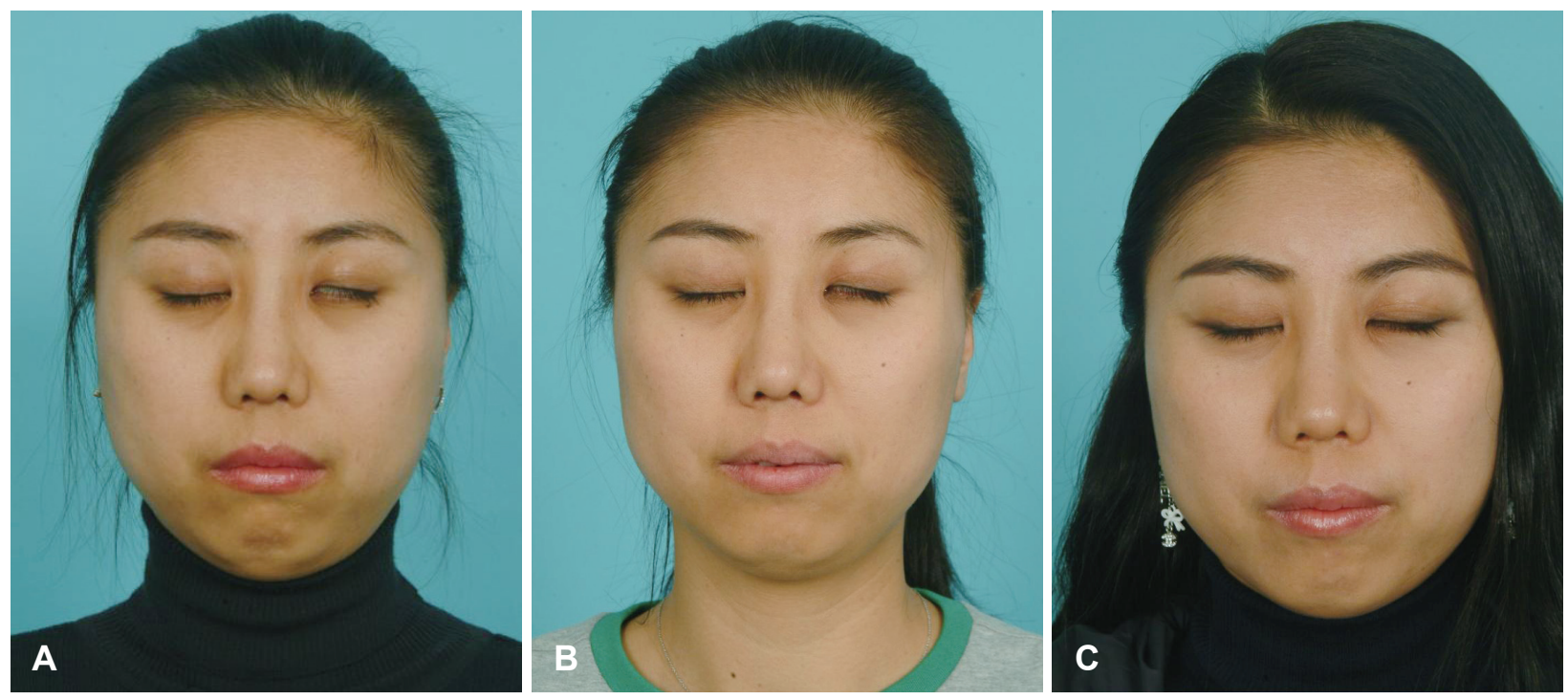

Fig. 2. Facial photos show the patient symptoms improved gradually over 3 months. Incomplete eye closure is observed in postoperative (POD) 1 week (A), a slightly improved status in POD 3 weeks (B), and a completely relieved symptom in POD 3 months (C). 


\section{Discussion}

The word lagophthalmos refers to the symptoms of incomplete upper eyelid closure or impaired upper palpebral movement, associated with ocular hyperemia similar to a hare. Currently the term refers to a condition of ocular exposure due to incomplete upper palpebra function. The causes of this condition include a decrease in the orbicularis oculi muscle tone by the facial nerve paralysis, exophthalmos from orbital tumor, traumatic or cicatricial palpebra injury and thyroid diseases. Continuous ocular exposure in lagophthalmos frequently causes conjunctivitis and exposure keratitis. It may lead to more severe conditions, such as corneal drying, ulceration and blindness. The patient in our case also presented exposure keratitis and corneal erosion due to lagophthalmos.

During a corrective rhinoplasty, various surgical techniques such as osteotomies or spreader grafts are used for the modification of the deviated external nose. These methods may cause bleeding, edema, canthal ligament damage, dysosmia, nasal obstruction, and other numerous complications. Ecchymosis, also a complication of corrective rhinoplasty, is developed by an injury to the lateral nasal artery branches or nasal mucosa. ${ }^{3)}$ Others, such as hematoma, may lead to visual impairment or conjunctival congestion, whereas a ligament injury may cause diplopia.

Percutaneous transverse osteotomy, one of the procedures of corrective rhinoplasty, was first introduced by Goria in 1955 and became widely known by Straatsma. ${ }^{4,5)}$ It is indicated when the medial and lateral fracture lines do not intersect after endonasal osteotomies. This surgical procedure initiates with a vertical stab incision just above the medial canthus. A $2 \mathrm{~mm}$ osteotome is then used to completely fracture the lateral wall transversely from just above the canthus to open roof. Because the procedure demands the surgeon's tactile sensation with limited visualization, it is an invasive method, $\left.{ }^{6}\right)$ with the risks of injury to the vessels, supporting mucosa and periosteum. $^{6,7)}$

In our case, left percutaneous transverse osteotomy was performed after medial and lateral osteotomies. The procedure was done on the left medial canthus with a 2-mm osteotome, which led to excessive bleeding caused by injury of the left dorsal nasal artery. In the left periorbital region, ecchymosis and edema dominantly surrounded the upper palpebra. These postoperative physical findings were subsided 7 days after the operation; however, the patient suffered from left orbital pain, continuous epiphora, and incomplete closure of the left upper eyelid.

To verify the cause of these findings, EMG was done after two weeks from the operation. During EMG, separate needle electrodes were inserted in the medial and lateral side of the palpebrae, both resulting in normal action potentials. ${ }^{8)}$ From these results, we assumed that the patient's upper eyelid paralysis did not indicate high possibilities of severe or irreversible facial nerve injury. Also, Bell's palsy was differentiated from diagnosis as the palsy was localized only on the medial upper eyelid. ${ }^{9)}$ Furthermore, the possibility of direct muscle injury by osteotome was very low since the percutaneous transverse osteotomy site was relatively distant from the orbicularis oculi muscle.

Thus, we predicted that the intraoperative bleeding that developed from the percutaneous transverse osteotomy led to hematoma on the medial left upper palpebra, obstructing the nerve conduction stimulation of the temporal branches of the facial nerve which innervates to the orbicularis oculi muscle. In other words, the hematoma caused increase of pressure of the facial nerve which led to neuropraxia. Neuropraxia is the 1st degree of nerve injury of Sunderland's classification indicating local myelin injury but no axon injury or Wallerian degeneration. ${ }^{10,11)}$ It is the least severe injury of the nerves which may cause a temporary paralysis of the nerve fiber and recovers in an average of 6 to 8 weeks. In our case, by resorption of hematoma and dissolving edema, the patient's recovery of the left upper eyelid paralysis was noticed within 3 weeks after the operation and full recovery after 3 months of the operation.

In the case of Bell's palsy, the disease generally develops suddenly with unknown causes. Maximum paralysis is observed within 48 hours of the onset, and more than $80 \%$ recovers after several weeks to months. Generally, a recovery is seen in 4 to 6 months, and the complete facial movements are noted within a year. ${ }^{12,13)}$ In our case, the definite onset of the facial paralysis was overshadowed by the immediate postoperative findings of periorbital hematoma. Based on the unknown onset time of the upper eyelid paralysis, improvement by the steroid therapy and the period of the full recovery, a differentiation from Bell's palsy may be argued. ${ }^{14)}$

In corrective septorhinoplasty, the surgeon should have a thorough knowledge of the intraoperative risks and potential complications of the various surgical techniques of the corrective rhinoplasty. When complications such as bleeding or hematoma occur during surgery, a rapid and intensive care is recommended for the early management and better prognosis of the postoperative complications. 


\section{REFERENCES}

1) Padovan IF, Jugo SB. The complications of external rhinoplasty. Ear Nose Throat J 1991;70(7):454-6.

2) Dziewulski P, Dujon D, Spyriounis P, Griffiths RW, Shaw JD. A retrospective analysis of the results of 218 consecutive rhinoplasties. Br J Plast Surg 1995;48(7):451-4.

3) Gryskiewicz JM, Gryskiewicz KM. Nasal osteotomies: a clinical comparison of the perforating methods versus the continuous technique. Plast Reconstr Surg 2004;113(5):1445-56; discussion 1457-8.

4) Denecke HJ, Meyer R. Plastic Surgery of the Head and Neck: Corrective and Reconstructive Rhinoplasty. New York: Springer-Verlag;1967.

5) Straatsma CR. Surgery of the bony nose: comparative evaluation of chisel and saw technique. Plast Reconstr Surg Transplant Bull 1961; 28:246-8.

6) Seiff SR. Surgical management of seventh nerve paralysis and floppy eyelid syndrome. Curr Opin Ophthalmol 1999;10(4):242-6.

7) Lee HM, Kang HJ, Choi JH, Chae SW, Lee SH, Hwang SJ. Rationale for osteotome selection in rhinoplasty. J Laryngol Otol 2002;116(12): 1005-8.
8) Tardy Jr MA, Denneney JC. Micro-osteotomies in rhinoplasty. Facial Plast Surg 1984;1:137-41.

9) Van de Graaf RC, IJpma FF, Nicolai JP. Lagophthalmos or hare eye: an etymologic eye opener. Aesthetic Plast Surg 2008;32(3):573-4.

10) Pirrello R, D’Arpa S, Moschella F. Static treatment of paralytic lagophthalmos with autogenous tissues. Aesthetic Plast Surg 2007; 31(6):725-31.

11) Vagefi MR, Winn BJ, Lin CC, Sires BS, LauKaitis SJ, Anderson RL, et al. Facial nerve injury during external dacryocystorhinostomy. Ophthalmology 2009;116(3):585-90.

12) Behrman JE, Acland RD. Experimental study of the regenerative potential of perineurium at a site of nerve transection. J Neurosurg 1981;54(1):79-83.

13) Dumitru D, Walsh NE, Porter LD. Electrophysiologic evaluation of the facial nerve in Bell's palsy. A review. Am J Phys Med Rehabil 1988;67(4):137-44.

14) Seiff SR, Seiff BD. Anatomy of the Asian eyelid. Facial Plast Surg Clin North Am 2007;15(3):309-14, v. 